\title{
PARÂMETROS HEMATOLÓGICOS E BIOQUÍMICOS DA ESPÉCIE Iguana iguana: REVISÃO DE LITERATURA
}

\author{
Mayra Dias SILVEIRA ${ }^{1}$, José Edgard de Oliveira ALVES ${ }^{1}$ \& Evelyn Mayara Perrut VIEIRA ${ }^{2}$ \\ 1 Universidade Federal Rural do Rio de Janeiro. Seropédica, Rio de Janeiro, Brasil. \\ 2 Universidade Severino Sombra. Vassouras, Rio de Janeiro, Brasil. \\ *Autor para correspondência: mayraa_dias@hotmail.com
}

DOI: http://dx.doi.org/10.18571/acbm.135

\section{RESUMO}

A espécie Iguana iguana, popularmente conhecida como iguana verde, é um réptil da família Iguanidae, encontrada no Brasil na região amazônica, região centro-oeste, pantanal e na caatinga. Estes animais possuem características intrínsecas em sua biologia e quaisquer perturbações no meio externo ou interno podem gerar repercussões importantes clinicamente e laboratorialmente. $\mathrm{O}$ crescente interesse por pets exóticos e a escassez de informações acerca das alterações fisiopatológicas envolvidas nos diversos processos de saúde-doença destes animais fundamentam a necessidade de maiores estudos abordando os aspectos clínicos e laboratoriais com vistas a uma melhor conduta preventiva e terapêutica. $\mathrm{O}$ presente artigo teve como objetivo revisar os conceitos vigentes da hematologia e da bioquímica de iguanas verdes.

Palavras-chave: Iguanidae; Répteis; Patologia clínica.

\begin{abstract}
Hemathological and biochemical paramaters of Iguana iguana species - review. The Iguana iguana species, popularly known as green iguana, is a reptile of the Iguanidae family, found in Brazil's Amazon region, midwestern region, pantanal and caatinga. These animals possess intrinsic characteristics in their biology and any disturbances in the internal or external environment can generate important repercussions clinically and laboratorially. The increased interest in exotic animals and the scarcity of information about the pathophysiological changes involved in the several health and illness processes in these animals support the need for further studies approaching clinical and laboratorial features to better preventive and therapeutic management. The present article aimed to review the current concepts of hematology and the biochemistry of green iguanas.
\end{abstract}

Keywords: Iguanidae; Reptiles; Clinical pathology.

\section{Introdução}

De acordo com o levantamento coordenado pela Sociedade Brasileira de Herpetologia, até o ano de 2005 eram conhecidas 641 espécies de répteis no território brasileiro, representando cerca de $8 \%$ das mais de oito mil espécies conhecidas no mundo (MARTINS; MOLINA, 2008). A espécie Iguana iguana, réptil da família Iguanidae, se distribui do México ao Brasil Central e Paraguai (VITT et al, 2008). No Brasil, é encontrada em parte da região Centro-Oeste, Pantanal e na Caatinga (CAMPOS, 2003). Quando jovens, alimentam-se principalmente de insetos e na vida adulta são herbívoros generalistas. São lagartos de grande porte, com coloração que pode variar entre verde intenso, verde acinzentado ou vermelho acinzentado (ANDRADE, 2009).

Poucos estudos foram realizados em iguanas verdes para se determinar como interpretar a patologia clínica nesta espécie. Parâmetros hematológicos e bioquímicos séricos em reptilianos 
podem variar de acordo com o gênero, idade, estado nutricional, estado fisiológico e pela variação da temperatura e outros fatores ambientais (CAMPBELL, 2006). Segundo Divers (1996), a necessidade de informações sobre as alterações fisiológicas e patológicas é crescente na medicina clínica de répteis. Nas últimas décadas esses animais vêm sendo cada vez mais vistos como pets exóticos ou expostos em zoológicos. Portanto, o conhecimento sobre a ecologia e a biologia da espécie é necessário para avaliação da saúde desses indivíduos em cativeiro e a carência de estudos expõe a importância de investigações mais aprofundadas, visto que os valores hematológicos e bioquímicos normais, mesmo para as espécies mais populares, ainda são de conhecimento insuficiente.

Diante do exposto, o presente artigo tem como objetivo revisar os conceitos da hematologia e bioquímica clínicas em iguanas verdes, abordando desde o manejo do animal no ato da colheita de sangue até a interpretação dos resultados obtidos nos exames laboratoriais.

\section{Desenvolvimento}

\subsection{A espécie estudada}

A Iguana iguana, popularmente conhecida como iguana verde ou iguana comum. É uma espécie distribuída do México, através da América Central e parte das Antilhas, ao Brasil Central e Paraguai. São répteis pertencentes à ordem Squamata, subordem Lacertilia, da família Iguanidae (VITT et al., 2008). No Brasil, tem distribuição na região Amazônica, parte da região CentroOeste, Pantanal e na Caatinga (CAMPOS, 2003). Os lagartos da família Iguanidae apresentam estruturas corporais características, dentre elas: uma crista parecida com espinhos ao longo do dorso e da cauda, uma escama grande e arredondada abaixo dos tímpanos e uma prega gular bem desenvolvida. São lagartos de grande porte, podendo pesar até seis quilos. Quando jovem, assume uma coloração verde intensa e, à medida que se aproximam da fase adulta, sua coloração varia do verde acinzentado ao cinza avermelhado, algumas vezes com listras verticais escuras distribuídas ao longo do corpo e da cauda (ANDRADE, 2009). Medem cerca de quarenta centímetros de comprimento rostro-cloacal e, incluindo a cauda, podem atingir um metro e cinquenta centímetros de comprimento na fase adulta (VITT et al., 2008).

O meio mais confiável de determinar o gênero de lagartos adultos é através dos poros femorais e pré-cloacais, que, quando presentes, são maiores em adultos machos do que em fêmeas (BARTEN, 2006). As iguanas atingem a maturidade sexual a partir do segundo ou terceiro ano de vida e se reproduzem uma vez ao ano, geralmente entre os meses de outubro a abril (ANDRADE, 2009).

Por serem ectotérmicos, repteis são dependentes das condições ambientais para controlar a temperatura corporal e regular seu metabolismo (ROSENTHAL, 2002). De acordo com Barten (2006), a ecologia térmica dos répteis é complexa e envolve muitos fatores. Nos lagartos, o mecanismo de regulação térmica atinge um maior grau de refinamento comparado com o restante dos reptilianos e grande parte das atividades diárias de lagartos é despendida em interações com o ambiente térmico. A perda ou ganho de calor depende tanto do habitat em que o lagarto se encontra quanto da atividade que ele esteja exercendo naquele determinado momento, como forrageamento, digestão de alimentos, reprodução e interações sociais (ROCHA et al., 2009).

Segundo Rocha et al. (2009), os lagartos herbívoros, assim como a Iguana iguana, precisam manter suas temperaturas elevadas para digerir a matéria vegetal ingerida. A radiação solar direta não é apenas a principal fonte de calor, mas também da radiação ultravioleta (UV). A luz UV aumenta a atividade em lagartos e cobras e a exposição a certos comprimentos de onda é essencial para a saúde dos lagartos com hábitos diurnos, pois a luz UV está diretamente relacionada com a síntese de vitamina D3. Esta vitamina é necessária para o metabolismo do cálcio da dieta, uma vez que a hipovitaminose $\mathrm{D}$ leva ao raquitismo e osteomálacia. Outro efeito de um desequilíbrio no 


\section{Biomedica Brasiliensia}

ISSN: $2236-0867$

cálcio é a produção de ovos mal calcificados, elevado número de ovos inviáveis e pouco sucesso de eclosão (DICKINSON; FA, 1997).

A umidade é um fator importante, mas muitas vezes esquecido no manejo de lagartos em cativeiro. Em geral, as espécies de florestas tropicais precisam de umidade maior que espécies de deserto. A maioria das espécies ficam bem em níveis de umidade entre 50\% a 70\%. (BARTEN, 2006).

As iguanas verdes são herbívoros e em vida livre se alimentam quase inteiramente de folhas, flores e frutos. Seu trato gastrointestinal é composto por esófago, estômago monocavitário, um intestino delgado curto, um intestino grosso com um cólon largo e compartimentado, reto e cloaca. É no cólon que ocorre a fermentação no intestino grosso (DIAZ-FIGUEROA; MITCHEL, 2006). A dieta herbívora é uma estratégia de alimentação incomum na maioria dos lagartos, entretanto, isso ocorre principalmente na família dos Iguanídeos e a iguana verde é um dos mais folívoros (BAER et al., 1997).

A dieta recomendada por Barten (2002) para iguanas verdes em cativeiro inclui uma variedade de vegetais verdes folhosos e cortados. Mesmo que as fontes de proteína animal tenham sido tradicionalmente recomendadas para iguanas, a sua necessidade não foi cientificamente comprovada, portanto a proteína fornecida deve ser de fonte vegetal. Os grãos devem ser limitados a petiscos ocasionais ou serem totalmente evitados na dieta. A suplementação com vitaminas e minerais é indicada em todas as fases de desenvolvimento de iguanas.

\subsection{Métodos de contenção e colheita de sangue}

Existem duas formas de se conter os animais: a contenção química e a contenção física. A contenção química produz efeitos comportamentais no animal, tais como sedação, analgesia, ou relaxamento muscular através do uso de fármacos, que facilitam sua manipulação. Já os métodos de contenção física incluem o uso de gaiolas, caixas, e armadilhas, dentre outros, visando o bemestar do animal, para que este tenha um manejo adequado e seguro (SANTOS; ZAPPA, 2009). Lagartos possuem um potencial de perigo aos manipuladores devido às estruturas dentais, que variam entre as espécies entre placas ósseas duras a dentes afiados; suas caudas, que podem ser utilizadas como armas de defesa causando pequenas escoriações ou até lesões graves ao manipulador; e suas garras longas, que também apresentam perigo, infligindo arranhões desagradáveis (FOWLER, 2008).

A contenção física de um iguana agressivo deve ser feita pela parte superior do animal, fixando a cabeça e cauda ao mesmo tempo. Deve-se ter cuidado ao manipular a cauda do animal, para se evitar a autotomia. Por este motivo nunca se deve realizar a contenção pelo agarramento ou levantamento dessa estrutura. Com o auxílio de uma toalha é possível que o animal seja envolvido, protegendo o manipulador do ataque de dentes, garras e cauda. Com uma mão o manipulador deve segurar ao redor do pescoço acima dos ombros do animal. O polegar e o dedo indicador devem estar posicionados caudalmente à cabeça para evitar mordidas. A segunda mão deve estar segurando os membros posteriores e a base da cauda (BARTEN, 2006). Lagartos de grande porte podem ser contidos através de redes ou cambões. Deve-se ter o cuidado com a tensão provocada no pescoço e pela força dos próprios animais na intenção de escapar (FOWLER, 2008).

Para a avaliação do estado de saúde do réptil, a colheita de uma amostra de sangue venoso é indicada para se obter os parâmetros hematológicos do animal (SCHUMACHER; YELEN, 2006). Lagartos possuem uma veia na região ventral da cauda. Neste local, a colheita se dá pelo posicionamento do animal em uma superfície em decúbito dorsal, localizando-se o processo espinhoso ventral de uma das vertebras caudais. Introduz-se uma agulha de 25 ou 22 gauge acoplada a uma seringa de 1 ou $3 \mathrm{~mL}$, direcionando-a num ângulo de 45 graus paralelamente ao processo espinhoso até que ponta da agulha encoste na estrutura óssea, puxando o embolo para trás (FOWLER, 2008). 
Uma via alternativa de acesso a ser considerada é feita através da veia abdominal ventral de lagartos, que se estende ao longo da parede abdominal na linha mediana (BARTEN, 2006). Essa veia possui grande calibre e pode ser utilizada para colheita de amostra sanguínea. $\mathrm{O}$ acesso é mais fácil quando feito na região celômica caudal, cranial à cicatriz umbilical. A agulha é posicionada na linha mediana ventral e avançada na direção craniodorsal. Outros acessos para punção venosa em lagartos são a veia jugular, plexo axilar, seio orbital e cardiocentese (DIVERS, 1996).

Todo o sangue obtido deve ser depositado em tubos heparinizados de lítio, pois o ácido etilenodiamino tetracético (EDTA) pode causar lise de eritrócitos. O volume de sangue em répteis varia de $5 \%$ a $8 \%$ do peso corporal total. Em uma aproximação grosseira, o volume retirado para a amostra não deve ser maior do que $1 \%$ do peso total do corpo do animal (MADER; RUDLOFF, 2006).

\subsection{Hematologia clínica de iguanas}

O sangue de répteis é composto por eritrócitos nucleados, plaquetas nucleadas (trombócitos), heterófilos, eosinófilos, basófilos, linfócitos e monócitos (CAMPBELL, 2006). A avaliação hematológica começa com a colheita de amostras de sangue, técnicas de manipulação das amostras e procedimentos laboratoriais (STACY et al., 2011). Cuidados devem ser tomados na utilização de anticoagulantes. A heparina de lítio, embora seja normalmente utilizada como anticoagulante na colheita de sangue de répteis, pode conferir uma coloração azul para a coloração total da película de sangue, provocando o acumulo de leucócitos e trombócitos, causando variação na contagem de células. A amostra deve ser processada imediatamente para minimizar os efeitos da heparina sobre as células. Sempre que possível, o exame de esfregaço deve ser obtido a partir de sangue fresco, sem anticoagulantes.

Doenças sistêmicas podem se manifestar no hemograma de répteis, alertando o médico veterinário para a necessidade da análise de outros exames laboratoriais (NARDINI et al., 2013). Variações nos valores de eritrócitos podem indicar anemia ou policitemia, que são classificadas de acordo com as alterações clínicas apresentadas. Além disso, o estudo do hemograma pode revelar a presença de hemoparasitas, que são achados comuns nestes animais. Da mesma maneira, o aumento ou redução do número de leucócitos totais pode nos indicar processos infecciosos ou doenças virais (FALCE, 2009).

A rotina da avaliação hematológica dos répteis inclui a determinação de hematócrito ou volume globular (Ht ou VG), hemoglobina $(\mathrm{Hb})$, contagem de hemácias, contagem de leucócitos (leucometria global), contagem diferencial de leucócitos (leucometria específica) e avaliação da morfologia das células do sangue (NARDINI et al., 2013). Os valores hematológicos para a espécie Iguana iguana encontram-se na Tabela 1.

O hemograma é uma mensuração valiosa da saúde em iguanas, mas os valores de referência para a maioria dos répteis não são conhecidos. Valores baixos de leucócitos podem ou não ser associados com doença viral, sequestro de células ou supressão da medula óssea. Erros na confecção de esfregaços levam a contagens mais baixas de leucócitos equivocadas. A elevação dos leucócitos é supostamente relacionada com doenças inflamatórias, infecciosas e neoplasias. Nas iguanas, os heterófilos são mais comuns que os linfócitos e os eosinófilos e basófilos são pouco visualizados se comparados aos outros leucócitos. Em casos de doenças inflamatórias e infecciosas, especialmente devido à cronicidade, os monócitos se mostram elevados. O monócito azurofílico, ou simplesmente azurófilo, parece estar elevado em doenças infecciosas e quanto mais alta for sua contagem, mais severa será a infecção (ROSENTHAL, 2002). Ainda este autor comenta que é esperado que a maioria dos répteis tenham um hematócrito mais baixo do que o esperado em mamíferos. Quando o hematócrito se apresenta alto em sua contagem, associado à dosagem de proteína total, possivelmente há uma desidratação, quadro comum em répteis devido 
a erros de manejo. Quando o hematócrito apresenta-se baixo, casos de anemia e doença crônica devem ser considerados.

\subsubsection{Eritrócitos}

Os eritrócitos de répteis são similares em morfologia microscópica e estrutural aos de outros vertebrados não mamíferos, como aves, anfíbios e peixes. São nucleados maiores do que os seus homólogos encontrados nos mamíferos. (STACY et al., 2011).

São produzidos na medula óssea a partir de células da linhagem eritróide, mas, diferentemente dos mamíferos, podem ser geradas em outros sítios hematopoiéticos, como o fígado e baço (FALCE, 2009).

Os estágios iniciais dos eritrócitos são normalmente encontrados no sangue dos répteis, representando $1 \%$ do total da contagem de glóbulos vermelhos em animais saudáveis. Este baixo número em comparação com os mamíferos e aves, se dá provavelmente por conta do ritmo lento de produção e rotatividade dos eritrócitos de répteis, da grande vida útil dos eritrócitos (de 600800 dias em algumas espécies) e de sua baixa taxa metabólica (NARDINI et al., 2013). Frequentemente são menores do que eritrócitos maduros, redondos ou irregulares, com grandes núcleos redondos e citoplasma basofílico. Podem ser vistos no sangue periférico de répteis muito jovens ou submetidos à ecdise. (CAMPBELL, 2006).

\subsubsection{Trombócitos}

Segundo Falce (2009), a produção de trombócitos nos répteis é similar à das aves. São células nucleadas, variando entres formas elípticas e fusiformes. Dentre suas funções, destacamse a sua capacidade de fagocitose, participando ativamente na defesa do organismo, a sua capacidade de se transformar em eritrócitos e a sua participação crucial na hemostasia, participando do mecanismo de coagulação. Trombócitos com núcleos polimorfos podem indicar doenças inflamatórias de caráter grave e trombócitos reativos são encontrados em quadros de sepse severa, como a causada por Salmonella. A trombocitopenia - redução da quantidade de trombócitos - nos répteis geralmente é associada ao excesso de utilização ou deficiência na produção, onde pode ser observada em casos de coagulação intravascular disseminada (CID).

\subsubsection{Leucócitos}

Segundo Stacy et al. (2011), os leucócitos reptilianos são classificados em granulócitos (heterófilos, eosinófilos e basófilos) e de células mononucleares (linfócitos, monócitos e azurófilos). Os granulócitos de répteis podem ser classificados em acidófilos e basófilos, baseado sua aparência em esfregaços de sangue corados. Os acidófilos são divididos em heterófilos e eosinófilos (CAMPBELL, 2006).

\subsubsection{Basófilos, heterófilos e eosinófilos}

Os basófilos são pequenos e arredondados e possuem grânulos citoplasmáticos basofílicos metacromáticos, que podem camuflar o seu núcleo. Ao contrário de tartarugas e crocodilos, os lagartos tendem a ter pequenos basófilos (CAMPBELL, 2006). A função dos basófilos em repteis ainda não é bem entendida. O aumento do percentual de basófilos é relatado em certas hemoparasitoses e infecções virais.

Em geral os heterófilos equivalem aos neutrófilos de mamíferos, enquanto os monócitos e os linfócitos de répteis possuem morfologia e função similares aos das aves, peixes e mamíferos. Os azurófilos são exclusivos da ordem reptiliana (STACY et al., 2011). Estes apresentam-se como 
células redondas com citoplasma granuloso cor de laranja, em formato fusiforme e eosinofílico. Estas células são facilmente identificadas por seu grande tamanho. Em lagartos, principalmente em Iguana iguana, o núcleo é geralmente bilobulado ou multilobulado (NARDINI et al., 2013).

Os heterófilos de iguanas possuem função análoga aos neutrófilos em mamíferos, incluindo fagocitose e atividade antimicrobiana (FALCE, 2009). Estudos funcionais em que heterófilos de aves foram comparados com neutrófilos de humanos e cães revelaram que os neutrófilos produzem substancialmente mais oxidantes em resposta a estímulos do que os heterófilos, presumivelmente por causa da atividade da peroxidase. Isto pode indicar que heterófilos em iguanas possuem capacidade bactericida e respostas oxidativas mais semelhantes às de neutrófilos de mamíferos do que heterófilos de aves ou outros répteis (HARR et al., 2001).

A morfologia dos eosinófilos de répteis se assemelha a dos mamíferos. Possuem um citoplasma com grânulos róseos (eosinofílicos), mas em algumas espécies, como em iguanas, os grânulos coram-se em azul. O núcleo geralmente é ovalado, único ou bilobado e localizado excentricamente (STACY et al., 2011). O número de eosinófilos é influenciado por fatores sazonais, com menores números reportados no verão e maiores números durante o período de hibernação. Os valores podem aumentar casos de parasitismo e estimulação imune inespecífica (STRIK et al., 2007). O significado da eosinopenia é desconhecido para repteis (IRIZARRYROVIRA, 2004).

\subsubsection{Azurófilos, monócitos e linfócitos}

Os azuróflos são um tipo de leucócito exclusivo para répteis. Combinam características morfológicas de monócitos e granulócitos em uma só célula. O citoplasma dos azurófilos contêm inúmeros grânulos eosinofílicos finos e parecidos com poeira. São comumente observados em lagartos, cobras e crocodilianos e ocasionalmente em quelônios (STRIK et al., 2007). Segundo Falce (2009), possuem tamanho e função semelhantes aos monócitos e assumem cerca de $20 \%$ dos leucócitos totais de Ball Pítons e Iguanas.

Os monócitos reptilianos se assemelham aos monócitos dos mamíferos. Possuem tamanho maior que as demais células de periferia e variam de formato circular à ameboide. O núcleo varia da forma oval a lobulada e possui menos cromatina condensada, o que o deixa com aspecto mais pálido quando comparado ao núcleo de linfócitos (FALCE, 2009). A presença de vacúolos e uma camada fina de grânulos azurofílicos também podem ser visualizados no citoplasma (HARR, 2001). As causas predominantes de monocitose em répteis são decorrentes de doenças inflamatórias agudas ou em processos inflamatórios crônicos devido a infecções bacterianas, infecções micóticas, parasitismo, infecções virais, corpos estranhos, dano tecidual e neoplasias (IRIZARRY-ROVIRA, 2004).

Os linfoblastos, prolinfócitos e linfócitos maduros aparecem igualmente ao dos mamíferos e aves, e eles podem ser encontrados em órgãos linfopoiéticos, como o baço (FALCE, 2009). Os linfócitos possuem tipicamente um grande núcleo arredondado que é proporcionalmente maior em relação ao citoplasma. A cromatina nuclear é fortemente concentrada em linfócitos maduros (CAMPBELL, 2006). Na maioria das espécies de répteis, os linfócitos são predominantes e compõe cerca de $80 \%$ dos leucócitos. As causas de aumento do número de linfócitos incluem inflamação ou infecção, processos de cicatrização de feridas, parasitismo e doenças virais. A redução do número de linfócitos pode ser associada à desnutrição e excesso de corticosteroides endógenos e/ou exógenos (STACY et al., 2011).

\subsection{Bioquímica plasmática de iguanas}

Os perfis bioquímicos do sangue são muitas vezes utilizados para avaliar o estado fisiológico dos pacientes répteis. Porém, a bioquímica clínica de répteis ainda não atingiu o mesmo grau de 
análises e avaliações criticas como visto na medicina de mamíferos domésticos, devido a uma falta geral de estudos controlados, destinados a esclarecer o significado de mudanças nas análises bioquímicas do sangue dos répteis (CAMPBELL, 2006). A interpretação dos parâmetros bioquímicos do sangue nos répteis é, em muitos aspectos, semelhante à de mamíferos, mas devese considerar que as formas de controle da homeostase em répteis são diferentes dos mamíferos e aves (SILVESTRE et al., 2013).

As condições ambientais e os parâmetros fisiológicos, tais como estado nutricional, sexo, idade, estação do ano e estado fisiológico influenciam a bioquímica do sangue de répteis. Valores de referência normais para testes bioquímicos específicos de algumas espécies de répteis têm sido relatados em alguns estudos, mas em muitas vezes não são levadas em consideração variações das condições ambientais, parâmetros fisiológicos, sazonalidade e particularidades quanto a idade e sexo desses animais. Outras variações, tais como os métodos de recolhimento de amostras, manuseio e análise bioquímica também são pouco relatadas (CAMPBELL, 2006).

Segundo Rosenthal (2002), existe um número limitado de informações sobre a bioquímica plasmática em iguanas, o que torna a interpretação dos valores obtidos em exames laboratoriais muito difícil. Para a maioria das substâncias analisadas, a quantidade de informação tende a ser ainda menor, dificultando a determinação do significado de um valor fora da variação normal. Os valores bioquímicos encontram-se descritos na Tabela 1.

\subsection{1 Ácido úrico}

Por representarem o primeiro grupo de animais a se adaptar a um estilo de vida totalmente terrestre, os rins dos répteis evoluíram para maximizar a conservação da água. Isto é conseguido com relativamente poucos néfrons, uma taxa de filtração glomerular baixa, capacidade de cessar a filtração glomerular por completo em momentos de estresse hídrico e a produção de ácido úrico como o produto final do metabolismo de nitrogênio (HOLZ, 2006). O ácido úrico é considerado produto primário final do catabolismo de proteínas, nitrogênio não proteico e purinas em repteis terrestres e representa 80 a 90\% do nitrogênio excretado pelos rins (CAMPBELL, 2006).

Segundo Silvestre et al. (2013), embora os túbulos renais de répteis sejam muito eficientes na remoção de ácido úrico no sangue, concentrações maiores que $15 \mathrm{mg} / \mathrm{dL}$ podem estar associadas com doença renal e também relacionadas à ingestão recente de uma dieta rica em proteínas ou gota visceral. Outros fatores como elevados níveis de cálcio, hipervitaminose D ou pouca disponibilidade de água também fazem com que as concentrações de ácido úrico se elevem no sangue.

\subsubsection{Ureia}

Os valores normais para ureia sanguínea são baixos para a maioria dos répteis, pois, por serem uricotélicos, não formam ureia como produto final do metabolismo de nitrogênio, que é direcionado à biossíntese de purinas, resultando em ácido úrico (TESSEROLI, 2004).

Esta determinação tem alta variação sazonal, chegando a valores máximos durante a hibernação (SILVESTRE et al., 2013). Um aumento na concentração de ureia plasmática pode ser sugestivo de doença renal grave, azotemia pré-renal ou alta ingestão de ureia na dieta de répteis (CAMPBELL, 2006).

\subsubsection{Cálcio e fósforo}

O metabolismo de cálcio no sangue e a quantidade de cálcio plasmático ionizado dos répteis é mediado pelo paratormônio (PTH), calcitonina e vitamina D3 ativada (colecalciferol). Outros 
hormônios, como o estrogênio, tiroxina, e glucagon também podem influenciar o metabolismo do cálcio em répteis (CAMPBELL, 2006).

Segundo Divers (2000), a determinação da concentração plasmática de cálcio e fósforo é importante no diagnóstico de várias doenças. A relação cálcio/fósforo é provavelmente um bom indicador de doença renal em répteis. Uma relação de cálcio/fósforo $(\mathrm{Ca}: \mathrm{P})$ menor que 1:1 sugere doença renal (SILVESTRE et al., 2013).

Além disso, a concentração normal de cálcio plasmático varia com a espécie e o estado fisiológico do réptil (CAMPBELL, 2006). Em répteis cativos, a hipercalcemia iatrogênica é comum devido a dietas com excesso de cálcio e vitamina D3 ou pode ser observada também quando a amostra de sangue é lipêmica ou após anestesia com propofol em iguana comum. Raramente alguns casos de hipercalcemia podem ocorrer em neoplasias, hiperparatireoidismo primário e doença óssea osteolítica e acidoses metabólicas (SILVESTRE et al., 2013). Acreditase que a hipercalcemia possa ocorrer por causa do ciclo reprodutivo das fêmeas, que exibem características do metabolismo do cálcio semelhantes às de aves em fase de produção de ovos e também em resposta ao estrógeno e à atividade reprodutiva, onde podem ser observados valores de cálcio séricos de duas a quatro vezes o valor normal (LIMA et al., 2012).

Ocorre hipocalcemia na maioria dos répteis quando há deficiência de cálcio e vitamina D3 na dieta, quantidade excessiva de fósforo na dieta, alcalose, hipoalbuminemia ou hipoparatireoidismo. Em répteis herbívoros, assim como a iguana comum, o hiperparatiroidismo secundário nutricional é um distúrbio que causa a redução dos níveis de cálcio no plasma (CAMPBELL, 2006).

As situações mais comuns que provocam o aumento da concentração de fósforo no sangue incluem uma dieta com quantidade excessiva de fósforo, hiperparatiroidismo secundário, a hipervitaminose D3 e doenças renais. Observa-se hiperfosfatemia em amostras hemolisadas (SILVESTRE et al., 2013), devido à presença do fósforo no interior dos eritrócitos (RAMEH-DEALBUQUERQUE, 2007). A situação de hipofosfatemia em repteis pode ocorrer por anorexia, inanição, neoplasias ou deficiências nutricionais (SILVESTRE et al., 2013).

\subsubsection{Proteínas Totais}

Casos de hiperproteinemia em répteis incluem desidratação ou hiperglobulinemia associada a doenças inflamatórias crônicas. As hipoproteinemias estão geralmente relacionadas à má nutrição crônica, problemas digestivos como redução da absorção e má digestão de alimentos, enteropatias, perdas sanguíneas severas e doenças renais ou hepáticas crônicas. Quando mantidos em cativeiro, alguns indivíduos podem apresentar uma concentração maior de proteína total plasmática quando comparados às mesmas espécies de vida livre, devido a dietas prolongadas com alto teor de proteína (CAMPBELL, 2012).

\subsubsection{Enzimas hepáticas}

De acordo com Almosny e Monteiro (2007), o comportamento das enzimas hepáticas de répteis parece ser similar ao de aves. A ALT (alanina aminotransferase) não é um indicador sensível no diagnóstico da doença hepática em répteis e a concentração plasmática de AST (aspartato aminotransferase) não é órgão-específica porque essa enzima é encontrada em vários tecidos. Normalmente a elevação da sua atividade sugere doença hepática ou lesão muscular. Também afirmam que a atividade plasmática de lactato desidrogenase (LDH) é considerada como de maior distribuição em répteis e pode estar associada com lesão hepática, muscular esquelética ou cardíaca.

Silvestre (2013) menciona que pode ser observado aumento da enzima AST devido à agressividade e efeito hormonal em iguanas e seu aumento também pode ocorrer devido ao estresse 
após constantes manipulações e após anestesia com propofol. O mesmo autor observou também elevação nos níveis tanto de AST quanto de ALT em consequência ao uso contínuo de carprofeno.

Os ácidos biliares não tem sido estudados na maioria dos répteis e atualmente a sua aplicação clínica ainda está para ser determinada. Porém, estudos recentes indicam que, em iguanas, níveis de ácidos biliares superiores a $70 \mu \mathrm{mol} / \mathrm{L}$ estão associados a doenças hepáticas como cirrose, neoplasias e lipidose (SILVESTRE et al., 2013).

\subsubsection{Creatina Cinase $(C K)$}

Sabe-se que, em répteis, os níveis de CK variam drasticamente de animal para animal. É uma enzima derivada da atividade muscular esquelética e cardíaca, com quantidades pequenas nos rins. É considerada músculo-específica nas iguanas e sua elevação pode ser provocada por lesões musculares ou infecções crônicas (SILVESTRE et al., 2013). Almosny e Monteiro (2007) afirmam que a sua elevação pode ocorrer também após injeções intramusculares.

\subsubsection{Glicose}

O controle hormonal da glicemia pela insulina e glucagon pancreáticos em répteis é semelhante a mamíferos e outros vertebrados. A ação desses hormônios é afetada pela temperatura. A concentração de glicose no sangue dos répteis normais também varia de acordo com a espécie, estado nutricional e das condições ambientais. Por exemplo, tartarugas e jacarés sujeitos a um aumento de temperatura reagem de forma distinta, o que resulta em hipoglicemia em tartarugas e hiperglicemia em jacarés (CAMPBELL, 2006).

A hipoglicemia é observada em animais com privação alimentar, má nutrição, dietas com altos níveis proteicos, hepatopatias severas, sepse e doenças endócrinas (RAMEH-DEALBUQUERQUE, 2007). A hiperglicemia em repteis ocorre muitas vezes pelo resultado da administração iatrogênica e glicocorticóides em excesso. A hiperglicemia não é um indicador específico de doença pancreática ou diabetes mellitus, mas está mais relacionada à problemas metabólicos, doenças sistêmicas e variáveis fisiológicas (SILVESTRE et al., 2013).

\subsubsection{Triglicerídeos e colesterol}

O aumento da concentração plasmática de triglicérides e colesterol está associado à postura de ovos nas fêmeas e pode ser visto também em répteis com lipidose hepática. O aumento pósprandial é visto em algumas espécies de répteis (IRIZARRY-ROVIRA, 2004). Devido à ação da tireióde durante o período de ecdise, há diminuição nos níveis sanguíneos de colesterol nestes animais (RAMEH-DE-ALBUQUERQUE, 2007).

Tabela 1: Valores hematológicos e bioquímicos de referência para a espécie Iguana iguana.

\begin{tabular}{ccc}
\hline \multirow{2}{*}{ PARÂMETROS } & \multicolumn{2}{c}{ VALORES } \\
\cline { 2 - 3 } Hematologia & Machos & Fêmeas \\
VG $(\%)$ & $34(29,2-38,5)$ & $38(33-44)$ \\
Eritrócitos $\left(10^{6} / \mathrm{mL}\right)$ & $1,3(1,0-1,7)$ & $1,4(1,2-1,8)$ \\
$\mathrm{Hb}(\mathrm{g} / \mathrm{dL})$ & $8,6(6,7-10,2)$ & $10,6(9,1-12,2)$ \\
$\mathrm{VCM}(\mathrm{fL})$ & $266(228-303)$ & $270(235-331)$
\end{tabular}




\begin{tabular}{ccc} 
CHCM $(\mathrm{g} / \mathrm{dL})$ & $21,1(22,7-28)$ & $27,9(24,9-31,0)$ \\
Leucócitos $\left(10^{3} / \mathrm{mL}\right)$ & $15,1(11,1-24,6)$ & $14,8(8,2-25,2)$ \\
Fibrinogênio & $100(100-200)$ & $100(100-300)$ \\
Heterófilos $(\%)$ & $3,6(1,0-5,4)$ & $3,2(0,6-6,4)$ \\
Linfócitos $(\%)$ & $9,7(5,0-16,5)$ & $9,9(5,2-14,4)$ \\
Monócitos $(\%)$ & $1,3(0,2-2,7)$ & $1,2(0,4-2,3)$ \\
Azurófilos $(\%)$ & - & - \\
Eosinófilos $(\%)$ & $0,1(0,0-0,3)$ & $0,1(0,0-0,2)$ \\
Basófilos $(\%)$ & $0,4(0,1-1,0)$ & $0,5(0,2-2,1)$ \\
Bioquímica & $2,7(1,5-5,8)$ & $3,6(0,9-6,7)$ \\
Ácido Úrico (mg/dL) & $2,0(0-11)$ & $2,0(0-11)$ \\
BUN/Uréia (mg/dL) & $11,3(8,6-14,1)$ & $12,5(10,8-14,0)$ \\
Cálcio (mg/dL) & $5,3(3,2-7,6)$ & $6,3(2,8-9,3)$ \\
Fósforo (mg/dL) & $161(82-214)$ & $255(204-347)$ \\
Colesterol (mg/dL) & $166(70-244)$ & $170(105-258)$ \\
Glicose (mg/dL) & $53-691$ & $53-691$ \\
Triglicerídeos (mg/dL) & $5,4(4,4-6,5)$ & $6,1(4,9-7,6)$ \\
Proteínas Totais & $32(4-76)$ & $45(5-96)$ \\
ALT & $33(19-65)$ & $40(7-102)$ \\
AST & & \\
\hline
\end{tabular}

Fonte: Adaptado de MADEN (2006).

\section{Conclusão}

Concluímos que a espécie estudada apresenta particularidades fisiológicas importantes que se refletem através de seus parâmetros hematológicos e bioquímicos e sofrem influência de condições intrínsecas, como sexo e idade, e extrínsecas, tais como temperatura, umidade, dieta e regime de criação, e têm impacto direto nas condições de saúde destes animais. A crescente introdução destes animais como pets exóticos resulta também em maior demanda por assistência médica veterinária e as lacunas no conhecimento existente acerca dos parâmetros hematológicos e bioquímicos nesta espécie reforçam a necessidade de maiores estudos na área.

\section{Referências}

ALMOSNY, N. R. P.; MONTEIRO, A. M. Patologia clínica. In: CUBAS, Z. S. et al. Tratado de animais selvagens: medicina veterinária. São Paulo: Roca, 2007. p. 939-367.

ANDRADE, C. A. F. Iguana verde (Iguana iguana). Universidade Federal de Viçosa: MZUFV, Viçosa, 2009. 3 p.

BAER, D. J.; OFTEDAL, O. T., RUMPLER, W. V.; ULLREY, D. E. Dietary Fiber Influences Nutrient Utilization, Growth and Dry Matter Intake of Green Iguanas (Iguana iguana). The Journal of Nutrition, v. 127, p. 1501-1507, 1997.

BARTEN, S. L. Criação e manejo do iguana verde. In: Bayer Exotics Symposium: Selected Papers on the Green Iguana and Antimicrobials in Exotic Pets, p. 13-22, 2002.

BARTEN, S. L. Lizards. In: MADER, D. R. (Ed.). Reptile Medicine and Surgery. Florida: Ed. Sauders Elsevier, 2006. p. 59-77.

BJORNDAL, K. A. Digestive Efficiency in a Temperate Herbivorous Reptile, Gopherus polyphemus. Copeia. v. 3, p. 714-720, 1987. 
CAMPBELL, T. W. Clinical pathology of Reptiles. In: MADER, D. R. (Ed.). Reptile Medicine and Surgery. Florida: Ed. Sauders Elsevier, 2006. p. 453-470.

CAMPBELL, T. W. Clinical Chemistry of Reptiles. In: THRALL, M. A.; WEISER, G., ALLISON, R. W.; CAMPBELL, T. W. (Eds.). Veterinary Hematology and Clinical Chemistry. Iowa: Ed. Wiley-Blackwell Inc. p. 599-606, 2012.

CAMPOS, Z. M. S. Biologia reprodutiva de Iguana no rio Paraguai. Pantanal, Brasil. Corumbá: Embrapa - Comunicado Técnico nº 30, ISSN 1517-4875, 2003.

DIAZ-FIGUEROA, O.; MITCHELL, M.A. Gastrointestinal anatomy and physiology. In: MADER, D. R. (Ed.). Reptile Medicine and Surgery. Florida: Ed. Sauders Elsevier, 2006. p. $145-162$.

DICKINSON, H. C.; FA, J. E. Ultraviolet Light and Heat Source Selection in Captive SpinyVERS, S. J.; REDMAYNE, G.; AVES, K. Haematological and biochemical of 10 green iguanas (Iguana iguana). The Veterinary Record. London, v. 138, n. 3, p. 203-205, 1996.

DIVERS, S. J. Reptilian renal and reproductive disease diagnosis. In: FUDGE, A.M. Laboratory medicine - avian and exotic pets. Philadelphia: Saunders, 2000. p. 217-222.

FALCE, M. C. L. B. Hematologia de Répteis - Revisão Bibliográfica. 2009. 53 f. Trabalho de conclusão do curso (Clínica Médica e Cirúrgica de Animais Selvagens e Exóticos) - Universidade Castelo Branco, Rio de Janeiro. 2009.

FOWLER, M. E. Restraint and Handling of Wild and Domestic Animals. 3 ed. Iowa: WileyBlackwell. p. 470, 2008.

HARR, K. E.; ALLEMAN, A. R; DENNIS, P. M.; MAXWELL, L. K; LOCK, B. A.; BENNETT, R. A.; JACOBSON, E. R. Morphologic and cytochemical characteristics of blood cells and hematologic and plasma biochemical reference ranges in green iguanas. JAVMA, v. 218, n. 6, 2001 .

HOLZ, P. H. Renal Anatomy and Physiology. In: MADER, D. R. (Ed.). Reptile Medicine and Surgery. Florida: Ed. Sauders Elsevier, 2006. p. 135-144.

IRIZARRY-ROVIRA, A. R. In: COWELL, R.L. (Ed.). Veterinary clinical pathology secrets. Missouri: Ed. Sauders Elsevier Inc. Mosby, 2004. p. 314-336.

LIMA, D. J. S.; BASTOS, R. K. G.; SEIXAS, L. S.; LUZ, M. A.; BRANCO; R. E.; SOUZA, N. F.; MORAES, C. C. G.; MENESES, A. M. C. Variação sazonal dos valores de bioquímica sérica de jiboias amazônicas (Boa constrictor constrictor) mantidas em cativeiro. Biotemas, v. 25, n. 4, p. 165-173, 2012.

MADER, D. R.; RUDLOFF, E. Emergency and Critical Care. In: MADER, D. R. (Ed.). Reptile Medicine and Surgery. Florida: Ed. Sauders Elsevier, 2006. p. 533-548.

MARTINS, M. R. C.; MOLINA, F. B. Panorama Geral dos Répteis Ameaçados do Brasil. In: MACHADO, A. B. M.; DRUMMOND, G. M.; PAGLIA, A. P. Livro Vermelho da Fauna Brasileira Ameaçada de Extinção. Brasília, DF: MMA; Ed. Fundação Biodiversitas, Belo Horizinte, 2008. p. 326-377.

NARDINI, G.; LEOPARDI, S.; BIELLI, M. Clinical Hematology in Reptilian Species. Vet. Clin. Exot. Anim., v. 16, p. 1-30, 2013. 
RAMEH-DE-ALBUQUERQUE, L. C. Aspectos hematológicos, bioquímicos, morfológicos e citoquímicos de células sanguíneas em Viperídeos neotropicais dos gêneros Bothrops e Crotalus mantidos em cativeiro. 2007. 177 f. Tese (Doutorado em Patologia Experimental e Comparada) - Universidade de São Paulo, São Paulo. 2007.

ROCHA, C. F. D.; SLUYS, M. V; VTCIBRADIC, D.; KIEFER, M. C.; MENEZES, V. A.; SIQUEIRA, C. C. Comportamento de Termorregulação em Lagartos Brasileiros. Oecol. Bras., v. 13. p. 115-131, 2009.

ROSENTHAL, K. L. Patologia clínica do iguana verde. In: Bayer Exotics Symposium: Selected Papers on the Green Iguana and Antimicrobials in Exotic Pets, p. 23-26, 2002.

SANTOS, D.; ZAPPA, V. Contenção química e física em grandes felídeos - Revisão de literatura. Revista Científica Eletrônica de Medicina Veterinária, v. 35, n. 12. 2009.

SCHUMACHER, J.; YELEN, T. Anesthesia and Analgesia. In: MADER, D. R. (Ed.). Reptile Medicine and Surgery. Florida: Ed. Sauders Elsevier, 2006. p. 442-452.

SILVESTRE, A. M.; LAVIN, S. CUENCA, R. La bioquímica sanguínea en clínica de reptiles. Consulta Difus. Vet., v. 200, p. 31-40. 2013.

STACY, N. I.; ALlEMAN, A. R.; SAYLER, K. A. Diagnostic Hematology of Reptiles. Clin. Lab. Med., v. 31. p. 87-108. 2011.

STRIK, N.I.; ALLEMAN, A.R.; HARR, K.E. Circulating Inflammatory Cells. In: JACOBSON, E.R. Infectious Diseases and Pathology of Reptiles, Color Atlas and Text. New York: Ed. CRC Press, Boca Raton, 2007. p. 167-186.

TESSEROLLI, G. L. Análise hematológica e bioquímica em cágados pescoço-de-cobra (Hydromedusa tectifera) mantidos em cativeiro. 2004. 58 f. Dissertação (Mestrado Patologia Veterinária) - Universidade Federal do Paraná, Curitiba. 2004.

VITT, M. P. L. Guia de Lagartos da Reserva Adolpho Ducke. Amazonia Central. 1ª. Ed. Manaus: Áttema Design Editorial, 2008. 176 p. 